\title{
Neurological manifestations of patients with COVID-19: potential routes of SARS-CoV-2 neuroinvasion from the periphery to the brain
}

\author{
Zhengqian $\mathrm{Li}^{1, *}$, Taotao Liu ${ }^{1, *}$, Ning Yang ${ }^{1}$, Dengyang $\mathrm{Han}^{1}$, Xinning $\mathrm{Mi}^{1}$, Yue $\mathrm{Li}^{1}$, Kaixi Liu ${ }^{1}$, Alain Vuylsteke ${ }^{2}$, \\ Hongbing Xiang $(\bowtie)^{3}$, Xiangyang Guo $(\bowtie)^{1}$ \\ ${ }^{1}$ Department of Anesthesiology, Peking University Third Hospital, Beijing 100191, China; ${ }^{2}$ Department of Anaesthesia and Intensive Care, \\ Royal Papworth Hospital NHS Foundation Trust, Cambridge, UK; ${ }^{3}$ Department of Anesthesiology, Tongji Medical College, Huazhong \\ University of Science and Technology, Wuhan 430022, China
}

(C) Higher Education Press 2020

\begin{abstract}
Coronavirus disease 2019 (COVID-19), caused by severe acute respiratory syndrome coronavirus 2 (SARS-CoV-2), has caused a global pandemic in only 3 months. In addition to major respiratory distress, characteristic neurological manifestations are also described, indicating that SARS-CoV-2 may be an underestimated opportunistic pathogen of the brain. Based on previous studies of neuroinvasive human respiratory coronaviruses, it is proposed that after physical contact with the nasal mucosa, laryngopharynx, trachea, lower respiratory tract, alveoli epithelium, or gastrointestinal mucosa, SARS-CoV-2 can induce intrinsic and innate immune responses in the host involving increased cytokine release, tissue damage, and high neurosusceptibility to COVID-19, especially in the hypoxic conditions caused by lung injury. In some immunecompromised individuals, the virus may invade the brain through multiple routes, such as the vasculature and peripheral nerves. Therefore, in addition to drug treatments, such as pharmaceuticals and traditional Chinese medicine, non-pharmaceutical precautions, including facemasks and hand hygiene, are critically important.
\end{abstract}

Keywords coronavirus disease 2019 (COVID-19); SARS-CoV-2; neurological manifestations; neuroinvasion; brain

\section{Introduction}

By March 29, 2020, the coronavirus disease 2019 (COVID-19) outbreak had caused 634835 confirmed cases and 29957 deaths globally, more than caused by severe acute respiratory syndrome (SARS) (8273 cases, 775 deaths) in 2003 and Middle East respiratory syndrome (MERS) (1139 cases, 431 deaths) in 2013. Currently, there is no confirmed effective therapeutic strategy for COVID19 because the mechanism and progress of its pathology are poorly understood. The pathogen, severe acute respiratory syndrome coronavirus 2 (SARS-CoV-2), is

Received March 25, 2020; accepted April 3, 2020

Correspondence: Xiangyang Guo, puthmzk@hsc.pku.edu.cn; Hongbing Xiang, xhbtj2004@163.com

${ }^{*}$ Zhengqian Li and Taotao Liu contributed equally to this article and should be considered co-first authors. highly pathogenic and transmissible, creating severe challenges for the whole world. The most prevalent COVID-19 symptoms are respiratory system dysfunction, fever, and cough, and most of COVID-19 patients had abnormal computerized tomography chest examinations. Most deaths of COVID-19 patients are associated with dyspnea. Some patients with SARS-CoV-2 infection had fatigue, muscle soreness, acute respiratory distress syndrome (ARDS), and other symptoms [1], among which, ARDS is the main reason for the transfer of patients to an intensive care unit [2].

Recently, it has been noticed that some severely affected COVID-19 patients experience neurological symptoms. The National Health Commission of China issued an updated version of the Diagnosis and Treatment Guidelines for COVID-19, which includes the pathological findings of multiple organs found from autopsy analysis [3]. Pathological changes in the lung, spleen, hilar lymph nodes, heart, blood vessels, liver, gallbladder, kidney, adrenal gland, esophagus, stomach, intestines, and brain 
were described. Such comprehensive multi-organ damage indicates that COVID-19 patients should be treated promptly to limit complications beyond the lungs. In the brain, tissue congestion, and edema were observed. These changes in the brain may underlie the neurological symptoms in some COVID-19 patients. Characterization of 99 COVID-19 patients in Wuhan indicated that neurological complications such as headache (8\%), nausea and vomiting (1\%) can be observed [4]. A later retrospective study of 214 COVID-19 patients reported that the incidence of neurological damage caused by SARS-CoV-2 may reach $36.4 \%$ [5]. Specifically, more severe patients were likely to have neurologic symptoms such as cerebrovascular diseases, consciousness impairment, and skeletal muscle symptoms [5]. These data indicated that the neuroinvasive potential of SARS-CoV-2 may contribute to the respiratory failure of COVID-19 patients [6]. However, the research on novel coronavirus is still in its early stages, and there has been no direct evidence to date of SARS-CoV-2 invading the central nervous system (CNS).

SARS-CoV-2 shares a highly homologous sequence with two other human CoVs with lethal potential: severe acute respiratory syndrome coronavirus (SARS-CoV) and MERS-CoV [7]. Both SARS-CoV and MERS-CoV can directly cause brain damage in both experimental animals and patients [6]. Thus, the possibility that SARS-CoV-2 may enter the CNS and cause neurological damage is not negligible. In addition, both SARS-CoV-2 and SARS-CoV invade human cells via angiotensin-converting enzyme 2 (ACE2) [8], an important component of the reninangiotensin system (RAS) in the brain [9]. Therefore, we speculate that the ability of SARS-CoV to invade the CNS may also be possessed by SARS-CoV-2.

As a human respiratory coronavirus, SARS-CoV-2 infection causes inflammatory damage to most type II alveolar cells, which may be aggravated by ventilatorinduced lung injury following mechanical ventilation or extracorporeal membrane oxygenation treatment $[1,10,11]$. Furthermore, damage to the liver, heart, and kidney has been reported $[12,13]$. When we suggest the possibility of the virus invading the brain, it is not that we are ignoring the damage to multiple organs, including the lungs. Conversely, it is the ARDS caused by SARS-CoV-2 that leads to profound systemic hypoxemia and an inflammatory storm, which facilitates the entry of the virus into the brain. In this review, we focus on the potential routes by which SARS-CoV-2 may invade the brain on the basis of previous discoveries for other respiratory viruses with a neuroinvasive propensity and the concurrent neurological symptoms of patients with COVID-19 (Fig. 1).

\section{Peripheral nervous route}

With the increasing understanding of the disease, many non-pulmonary symptoms are now also recognized, especially neurological signs, including CNS and peripheral nervous system (PNS) symptoms [5]. The former include dizziness, headache, nausea, and vomiting, while the latter mainly include three kinds of hypoesthesia (hyposmia, hypogeusia, and hypopsia), indicating that the virus may enter the CNS and then damage certain nuclei or neural circuits. This viewpoint is supported by the

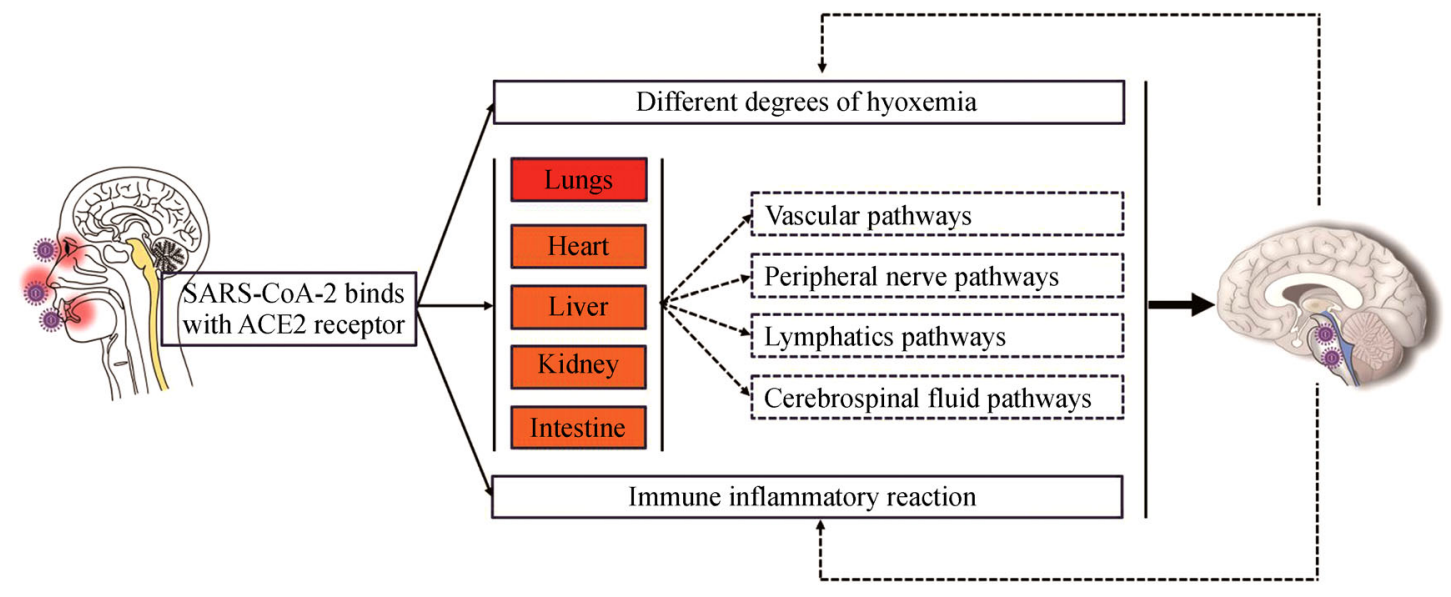

Fig. 1 The main organs and potential routes of SARS-CoV-2 neuroinvasion from the periphery to the brain. SARS-CoV-2 binds to angiotensin-converting enzyme type 2, which is widely distributed in the lungs, heart, liver, kidney, and intestine. SARS-CoV-2 induces the intrinsic immune response, a cytokine storm, acute respiratory distress syndrome, and damages peripheral tissues. It may simultaneously invade the brain through the vascular, peripheral nerve, lymphatics, and cerebrospinal fluid pathways. Consequently, the brain may be involved in the systemic response after being subjected to hypoxemia. 
neurotropic properties of two other coronaviruses that have caused epidemics or pandemics this century, MERS-CoV and SARS-CoV [14-18]; both share highly homologous sequences with SARS-CoV-2. In addition, postmortem studies of COVID-19 patients strongly indicate neurological pathology [3]. Droplet contagion is the main route of SARS-CoV-2 transmission (while close contact is also a significant route of infection); therefore, it is worth clarifying the potential intranasal and oral routes by which SARS-CoV-2 enters the CNS to understand the development of hyposmia, hypogeusia, and hypopsia. In general, there are two anatomical routes for a virus to enter the CNS, a neural pathway and a body fluid (such as blood, lymph, and cerebral spinal fluid). For a neural pathway, the virus must first enter a nerve terminal and replicate, then be retrogradely transported to the soma and invade the CNS (Fig. 2).
How does hyposmia occur in COVID-19? After droplets containing SARS-CoV-2 land in the nasal cavity, most viruses reach the lung through the airway, while some viruses adhere to the mucosa of the nasal cavity, pharynx, cavum larynges or trachea. When SARS-CoV-2 adheres to the nasal mucosa, it may directly infect olfactory sensory neurons in the olfactory epithelium and then be transported into the CNS through the olfactory nerve. This is supported by evidence from animal experiments investigating MERS-CoV [17] and SARS-CoV [19]. Alternatively, SARS-CoV-2 adhering to the nasal mucosa may infect the trigeminal nerve (a nasal cavity nociceptor), which has been investigated for drug delivery [20,21]. In addition, postmortem analyses of SARS patients from 2003 detected SARS-CoV particles in the brain that showed cellular selectivity, most assembling in neurons rather than glia [22-24]. It should also be noted that olfaction is affected by

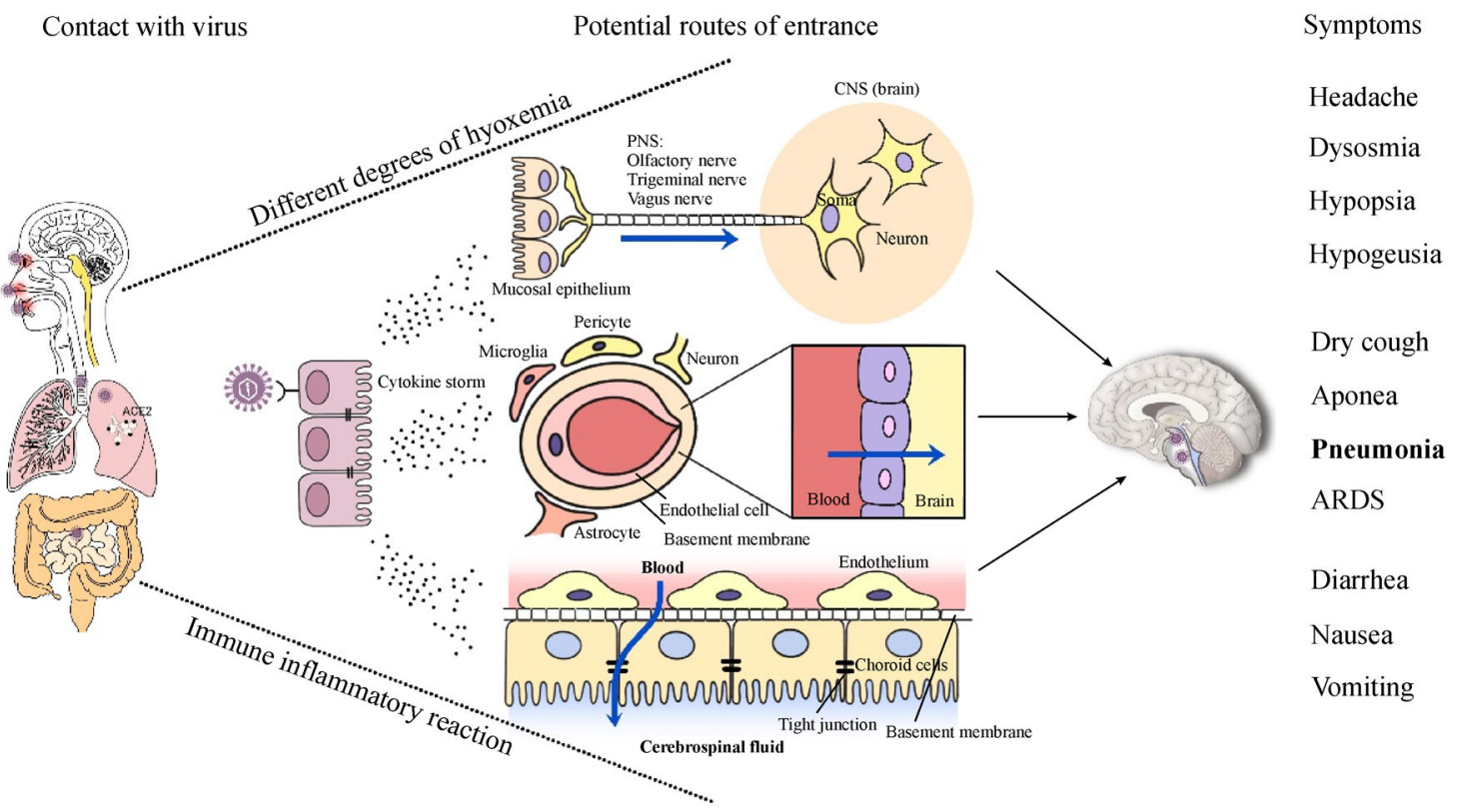

Fig. 2 Potential routes of SARS-CoV-2 neuroinvasion from the periphery to the brain. Inhalation droplets and close contact transmission are the main person-to-person transmission routes of COVID-19. Once the virus enters a host cell, the innate immune response may trigger a cytokine storm, especially under profound hypoxemia conditions induced by ARDS in patients with severe COVID-19. (i) When SARSCoV-2-carrying droplets contact the eye conjunctiva, they can enter the brain after infecting the trigeminal nerve (V), resulting in decreased vision. (ii) The virus may also infect the sensory neurons in the taste buds, ascend to the nucleus of the solitary tract (VII, IX, and $\mathrm{X}$ ) or trigeminal nerve (V) and enter the CNS through neuronal retrograde transport. (iii) Once the virus-containing droplets land on the nasal mucosa, SARS-CoV-2 may enter the brain along the olfactory nerve. In addition, the abundant capillary blood vessels and lymphatics underlying the nasal mucosa provide opportunities for virus invasion. (iv) Viruses that enter the respiratory tract flow into the bloodstream through ACE2 receptors expressed in the epithelial cells of the respiratory tract. In addition to the vascular pathways, the virus spreads toward the CNS through the vagus nerve branch $(\mathrm{X})$ that innervates the respiratory tract, resulting in dry cough, dyspnea, and exacerbating acute respiratory distress syndrome. (v) Similarly, poor hand hygiene gives the virus the opportunity to enter the gastrointestinal tract and then enter the brain through the vasculature, vagus nerve, and lymphoid pathways. These patients may experience loss of appetite, nausea, vomiting, and diarrhea. (vi) The virus that enters the circulation can invade the brain through the damaged BBB and leak into the interstitial fluid, and then enter the cerebral spinal fluid through the intracerebral lymphatic circulation. Viruses in the blood can also enter the fourth ventricle directly through a damaged blood cerebral spinal fluid barrier. 
other factors, such as nasal mucosa swelling and allergy.

In humans, the sense of taste is conveyed via three of the 12 cranial nerves, the facial nerve (VII), the glossopharyngeal nerve (IX), and the vagus nerve (X). Once the termini of these nerves are activated, the information first transfers to the nucleus of the solitary tract in the brainstem and then to the thalamus after substitution. Thus, hypogeusia caused by SARS-COV-2 infection could result from injury to any of these three nerves (VII, IX, and X), the nucleus of the solitary tract, or thalamic nuclei (Fig. 2). Similar to hyposmia, the hypogeusia seen in COVID-19 patients may be associated with SARS-CoV-2 CNS infection. For hypopsia, there is limited evidence supporting direct infection of the optic nerve by SARS-CoV-2. Recently, SARS-COV-2 RNA fragments were found in ocular discharge by SARS-COV-2 RT-PCR in one patient with conjunctivitis [25].

The nucleus of the solitary tract is very close to the respiratory center; therefore, it is possible that SARS-CoV2 from the nucleus of the solitary tract can infect the respiratory center, resulting in neurogenic refractory dyspnea $[6,26]$. Confirmation of this possibility would be helpful in understanding respiratory symptoms in different patients (Fig. 1). In addition, viruses in neurons "escape from immune surveillance" and can therefore replicate when the immunity of the host is impaired or weakened, which is similar to varicella-zoster virus [27,28]. A small group of COVID-19 patients who had recovered from the acute infection were recently tested for SARS-CoV-2 RNA and shown to still be positive. This may be because of the "escape from immune surveillance," meaning that a much longer period of treatment and supervision may be needed [6].

\section{Hematogenous route}

For hematogenous invasion, the virus must infect the endothelial cells of the blood-brain-barrier (BBB) or the blood-cerebrospinal fluid barrier (BCSFB), and then disseminate toward the CNS. Like SARS-CoV, the entry of SARS-CoV-2 into human host cells is mainly mediated by ACE2 [8], while MERS-CoV binds to dipeptidylpeptidase 4 (DPP4) [29]. ACE2 and DPP4 are located in multiple organs, including lung, kidney, heart, small intestine, testicle, and brain [30]; therefore, it is necessary to investigate the direct and indirect routes that these coronaviruses use to infect the CNS. In a SARS-CoVinfected transgenic mouse model of human ACE2, the olfactory nerve was the main pathway for the virus to enter the brain; however, there were still a number of infected sites indirectly connected with the olfactory bulb, indicating non-neuronal routes for viral infection, such as the hematogenous route [19].

Nevertheless, viral entry is a complicated multi-step process, involving virus attachment to the cell surface, receptor engagement, protease processing, and membrane fusion [31]. Like other CoVs, SARS-CoV-2 encodes spike, a surface glycoprotein that binds to ACE2 and mediates viral entry [31]. The spike protein is cleaved by nearby proteases and releases a signal peptide to facilitate virus entry into host cells [32]. SARS-CoV-2 has a higher affinity to ACE2 than SARS-CoV, which explains, in part, why SARS-CoV-2 more easily spreads human-to-human [33]. In the lungs of SARS-CoV infected mice, the spike protein downregulated ACE2 protein expression, which resulted in increased Ang II peptide levels and vascular permeability [34]. These animals showed disrupted barrier function and worsened ARDS symptoms. Similarly, SARS-CoV-2 mainly infects type II alveolar epithelial cells, which express high levels of ACE2 [30]. Therefore, it is not difficult to understand that SARS-CoV-2 binds to the ACE2 receptor on the alveolar epithelial cells, causing endothelial damage and entering the blood circulation. Because of the large surface area of pulmonary alveoli, virus invasion can be very fast and large-scale. The virus not only infects the epithelial cells, but also the resident, infiltrating, and circulating immune cells. The infected circulating immune cells carry the virus to other organs causing the extrapulmonary symptoms, including fever, myalgia, fatigue and kidney dysfunctions [35], acute myocardial injury [36], CNS and PNS symptoms [5] and maybe gastrointestinal symptoms. It is possible that other pathways exist for the virus to infect CNS, such as the viral RNA in the plasma directly infect the endothelial cells of the BBB with an unknown mechanism [37]. The infection to the cardiorespiratory center in the brain stem may cause central respiratory failure to progress rapidly (Fig. 1). This is why mechanical respiratory support and endotracheal intubation should be applied at the earliest sign of ineffective noninvasive ventilation.

Immunohistochemistry shows that ACE2 is localized in almost all human organs [38]. Once SARS-CoV-2 is present in the circulation, it can infect leucocytes that spread easily via the circulatory system, and reach remote tissues, causing multiple organ dysfunction (Fig. 1). Therefore, to avoid blood-borne infection of the CNS and further central respiratory failure, systematic antiviral therapy, and traditional Chinese medicine therapy should be administered as soon as possible. However, the efficacy of ACE inhibitor therapy has been controversial so far [39]. On the one hand, binding of the virus to ACE2 is not associated with the enzyme function of ACE2 [40], while the angiotensin-converting enzyme inhibitor (ACEI) targets the hydrolytic function of ACE2. On the other hand, ACE2 activation shows that lung-protective effects in lung injury and inhibition of Ang II degradation by ACE2 are likely to exacerbate the inflammatory response [41]. Local ACEI administration may be a better choice than a systematic ACEI application. 


\section{Digestive tract route}

Except for the respiratory tract, SARS-CoV-2 can also infect the gastrointestinal tract. A retrospective study of nine pregnant patients with SARS-CoV-2 infection found a case whose chief symptom was diarrhea [42]. Another study involving 1099 COVID-19 patients confirmed that nearly $10 \%$ of the patients had gastrointestinal symptoms, such as diarrhea and vomiting $[13,43]$. Furthermore, $\mathrm{CoV}$ nucleic acid has been detected in the stool of COVID-19 patients, indicating that the gastrointestinal system is a potential target of SARS-CoV-2 $[44,45]$.

As mentioned above, ACE2 is not only expressed in alveolar epithelial cells but also in intestinal epithelial cells. Single-cell RNA sequencing data show that expression of ACE2 in colon cells is positively correlated with genes regulating virus infection, and innate and cellular immunity, but negatively correlated with virus transcription, protein translation, humoral immunity, phagocytosis, and complement activation [46]. Based on these findings, SARS-CoV-2 may interact with ACE2 in the gastrointestinal tract and destroy the gastrointestinal epithelial cell barrier, increase the production of inflammatory cytokines, decrease gastrointestinal absorptive capacity, and increase secretion by the gastrointestinal mucosa. With the disruption caused by SARS-CoV-2 infection, increasing amounts of inflammatory factors are produced, which eventually leads to a cytokine storm. The spike protein of SARS-CoV2 is different from that of SARS-CoV in that SARS-CoV-2 spike has a site that is activated by furin, a host cell enzyme that is found in a variety of human tissues, including intestine and lung (Fig. 2). This may be one of the reasons why COVID-19 is more infectious than SARS [47].

A virus that enters the intestine binds to specific host-cell receptors to penetrate and infect host cells to produce more virions. Once sufficient virions have accumulated, they are released into the surrounding environment where they can infect more resident host cells. Enteroviruses, such as poliovirus, coxsackievirus, and echovirus, reproduce in the intestine and can invade intestinal epithelial cells [48]. The inflammatory response to host cell death can decrease the expression of the intestinal barrier proteins ZO-1, occludin or claudin 3, which disrupts the integrity of the intestinal barrier $[49,50]$. Besides, the inflammatory response can also trigger intestinal microbiota disorder, which aggregates the damage of the intestinal mucosa barrier structure [51]. Taking all these factors into account, the virus can easily enter the blood circulation through the cracked intestinal barrier, while viruses in lymphoid tissue can influence remote organs through the lymphatic pathway.

The virus can also invade local peripheral nerves and after replication can advance along their axons to the CNS. Herpes simplex viruses can spread via the dorsal root ganglia to the autonomic ganglia of the enteric nervous system in the colon [52]. Influenza A virus may have access to the CNS and alter the hippocampus function via the vagus nerve, affecting cognition and behavior [53,54]. Although there is no direct evidence to show that SARSCoV-2 can enter the CNS retrogradely via the intestinal branch of the vagus nerve, the disrupted gastrointestinal environment may influence the integrity of the BBB through immune, neural, and humoral pathways, thus facilitating the movement of the peripheral virus into the CNS. Last but not the least, the vomiting center receives neural signals from sensory receptors in the digestive tract and afferent fibers of the vagus nerve can form synapses in the solitary nucleus affecting the vomiting reflex. When neural signals exceed the threshold, the vomiting reflex is activated. Therefore, it is of great significance to pay attention to the nerve pathway between the digestive system and the CNS for the treatment of intestinal complications caused by viral infection.

In light of the possibility of fecal-oral transmission, masks and hand hygiene are fundamental and effective precautions. From the perspective of containing the virus, ACE2 inhibition and viral spike protein activation are potential targets for clinical intervention of the gastrointestinal symptoms of COVID-19 patients.

\section{Lymphatics and/or cerebrospinal fluid route}

It is reported that SARS-CoV can directly invade hilar lymph nodes and mesenteric root lymph nodes both in humans and civets $[55,56]$, indicating that lymph nodes, especially in the lung and intestine, are also main target organs. There is also an abundant lymphatic network in the mucosa of the eyes [57], oral tissues [58], and tracheal bronchus [59], which may be also invaded by SARS-CoV2. When peripheral lymphoid tissue is invaded, the virus eventually enters blood circulation via the flow of lymph fluid.

As mentioned above, the excess of free radicals, such as superoxide anions, nitric oxide (NO), and reactive oxygen/ nitrogen species (ROS) [60], and the cytokine storm induced by SARS-CoV-2 infection can cause severe inflammation and multiple organ damage, including severe BBB disruption, which leads to the entry of the virus into the brain via the hematogenous route [61]. The brain has its own lymphatic drainage system [62] and under normal physiologic conditions, cerebral solutes move in the interstitial fluid (ISF) and cerebral spinal fluid (CSF) through the glymphatic pathway. CSF from the subarachnoid space fluxes into the brain from perivascular spaces and exchanges with ISF. The bulk movement of CSF into the brain drives the convective flow of ISF and interstitial solutes to the peri-venous route [63]. However, this lymphatic drainage pathway in the brain can be destroyed under pathological conditions, such as virus 
infection [64], which leads to brain edema and changes in brain morphology, structure, and function, ultimately resulting in the consequence that virus overflows into the perivascular space and finally enters into the CSF (Fig. 2). This may be the main cause of CNS symptoms in severe or critical patients. A case report described a medical graduate student (24 years old) infected with SARS-CoV-2 who had to stay awake and breathe consciously and actively during intensive care. If not, she risked death because she was likely to stop breathing [6]. This indicates that for severe and critical patients, the virus enters the brain through a damaged blood-brain barrier and aggravates neurological symptoms and impairs consciousness, and even causes dysfunction of the cardiorespiratory center in the brainstem.

The nasal mucosa can be a route of entry for the virus. Both SARS-CoV and MERS-COV, when given intranasally, can enter the brain $[17,19]$. The perineural spaces that encompass olfactory nerves and the nasal lymphatics are important for CSF drainage [65]. After invading the nasal mucosa and reaching the lamina propria, SARS-CoV-2 may enter channels created by olfactory ensheathing cells surrounding the olfactory nerves, where they can access the CSF.

\section{Summary}

The novel human coronavirus, SARS-CoV-2, may be an underestimated opportunistic pathogen of the CNS. Once the virus enters a host cell, intrinsic and innate immune responses are triggered in the early stage of infection. The subsequent cytokine storm and systemic hypoxemia induced by respiratory distress may facilitate the entry of the virus into the brain. In severe ARDS-patients, secondary injury caused by mechanical ventilation or extracorporeal membrane oxygenation treatment may also be involved. SARS-CoV-2 may enter the brain of immunecompromised individuals through different routes involving the vasculature, the olfactory and trigeminal nerves, the cerebrospinal fluid, and the lymphatic system.

At present, it is difficult to determine which approach dominates. The pathway of the virus into the brain may be mainly related to the route of transmission and the distribution of intracellular receptors of the virus. The vascular pathway into the brain is theoretically fast, but only when the disease progresses to a certain extent and the BBB is dysfunctional. In addition, the neuronal retrograde transport in the peripheral nerve pathway is quite slow [65]. Nevertheless, the olfactory epithelium is characterized by the presence of olfactory sensory neurons $[17,19]$. The SARS-CoV-2 can enter the olfactory sensory neurons and replicate quickly. Furthermore, previous studies suggest that CoVs may first invade peripheral nerve terminals and then enter into the brain through a trans- synaptic transfer $[15,16,53]$. Considering the olfactory nerve is anatomically close to the center, the olfactory nerve pathway may be the main way for the virus to enter the brain in the early stage of infection.

Awareness of the potential neuroinvasion of SARSCoV-2 will have critical significance for the prevention and treatment of COVID-19. Multiple precautions and measures, including wearing masks and hand hygiene to prevent the virus from contacting and invading the human body, as well as advanced medical interventions are critically necessary. Clinical physical examination of the nervous system, pathogenic detection of CSF, early antiviral therapy with neuroprotection, and prompt endotracheal intubation and mechanical respiratory support should be proposed for early identification and timely management of neurological complications. Based on the previous human coronavirus epidemic outcomes, the longterm psychological and neurocognitive rehabilitation should not be ignored.

\section{Acknowledgements}

This work is funded by the National Natural Science Foundation of China (Nos. 81873726, 81971012, and 81901095), Peking University "Clinical Medicine plus X" Youth Project (No. PKU2020LCXQ016) and Key Clinical Projects of Peking University Third Hospital (No. BYSYZD2019027). We acknowledge all healthcare workers involved in the diagnosis and treatment of COVID-19 patients all around China. We acknowledge Edanz Group for the linguistic editing and proofreading during the preparation of this manuscript.

\section{Compliance with ethics guidelines}

Zhengqian Li, Taotao Liu, Ning Yang, Dengyang Han, Xinning Mi, Yue Li, Kaixi Liu, Alain Vuylsteke, Hongbing Xiang, and Xiangyang Guo declare no conflicts of interest. This manuscript is a review and does not involve a research protocol requiring approval by the relevant institutional review board or ethics committee.

\section{References}

1. Sun P, Qie S, Liu Z, Ren J, Li K, Xi J. Clinical characteristics of hospitalized patients with SARS-CoV-2 infection: a single arm meta-analysis. J Med Virol 2020 Feb 28. [Epub ahead of print] doi: 10.1002/jmv. 25735

2. Wang D, Hu B, Hu C, Zhu F, Liu X, Zhang J, Wang B, Xiang H, Cheng Z, Xiong Y, Zhao Y, Li Y, Wang X, Peng Z. Clinical characteristics of 138 hospitalized patients with 2019 novel coronavirus-infected pneumonia in Wuhan, China. JAMA 2020 Feb 7. [Epub ahead of print] doi: 10.1001/jama.2020.1585

3. National Health Commission of the People's Republic of China. The guidelines for the diagnosis and treatment of novel coronavirus (2019-nCoV) infection (trial version 7). 2020. http://www.nhc.gov. 
cn/yzygj/s7653p/202003/46c9294a7dfe4cef80dc7f5912eb1989. shtml (in Chinese) (accessed March 4, 2020)

4. Chen N, Zhou M, Dong X, Qu J, Gong F, Han Y, Qiu Y, Wang J, Liu Y, Wei Y, Xia J, Yu T, Zhang X, Zhang L. Epidemiological and clinical characteristics of 99 cases of 2019 novel coronavirus pneumonia in Wuhan, China: a descriptive study. Lancet 2020; 395 (10223): 507-513

5. Mao L, Wang MD, Chen SH, He QW, Chang J, Hong CD, Zhou YF, Wang D, Li YN, Jin HJ, Hu B. Neurological manifestations of hospitalized patients with COVID-19 in Wuhan, China: a retrospective case series study. medRxiv 2020; doi: 10.1101/ 2020.02.22.20026500

6. Li YC, Bai WZ, Hashikawa T. The neuroinvasive potential of SARS-CoV2 may play a role in the respiratory failure of COVID19patients. J Med Virol 2020 Feb 27. [Epub ahead of print] doi: $10.1002 / j m v .25728$

7. Grifoni A, Sidney J, Zhang Y, Scheuermann RH, Peters B, Sette A. A sequence homology and bioinformatic approach can predict candidate targets for immune responses to SARS-CoV-2. Cell Host Microbe 2020 Mar 16. [Epub ahead of print] doi : 10.1016/j. chom.2020.03.002

8. Hoffmann M, Kleine-Weber H, Schroeder S, Krüger N, Herrler T, Erichsen S, Schiergens TS, Herrler G, Wu NH, Nitsche A, Müller MA, Drosten C, Pöhlmann S. SARS-CoV-2 cell entry depends on ACE2 and TMPRSS2 and is blocked by a clinically proven protease inhibitor. Cell 2020 Mar 4. [Epub ahead of print] doi: 10.1016/j. cell.2020.02.052

9. Abiodun OA, Ola MS. Role of brain renin angiotensin system in neurodegeneration: an update. Saudi J Biol Sci 2020; 27(3): 905912

10. Sasannejad C, Ely EW, Lahiri S. Long-term cognitive impairment after acute respiratory distress syndrome: a review of clinical impact and pathophysiological mechanisms. Crit Care 2019; 23(1): 352

11. Harnisch LO, Riech S, Mueller M, Gramueller V, Quintel M, Moerer O. Longtime neurologic outcome of extracorporeal membrane oxygenation and non extracorporeal membrane oxygenation acute respiratory distress syndrome survivors. J Clin Med 2019; 8(7): E1020

12. Zhang C, Shi L, Wang FS. Liver injury in COVID-19: management and challenges. Lancet Gastroenterol Hepatol 2020 Mar 4. [Epub ahead of print] doi: 10.1016/S2468-1253(20)30057-1

13. Jiang F, Deng L, Zhang L, Cai Y, Cheung CW, Xia Z. Review of the clinical characteristics of coronavirus disease 2019 (COVID-19). J Gen Intern Med 2020 Mar 4. [Epub ahead of print] doi: 10.1007/ s11606-020-05762-w

14. Glass WG, Subbarao K, Murphy B, Murphy PM. Mechanisms of host defense following severe acute respiratory syndrome-coronavirus (SARS-CoV) pulmonary infection of mice. J Immunol 2004; 173(6): 4030-4039

15. Li YC, Bai WZ, Hirano N, Hayashida T, Hashikawa T. Coronavirus infection of rat dorsal root ganglia: ultrastructural characterization of viral replication, transfer, and the early response of satellite cells. Virus Res 2012; 163(2): 628-635

16. Li YC, Bai WZ, Hirano N, Hayashida T, Taniguchi T, Sugita Y, Tohyama K, Hashikawa T. Neurotropic virus tracing suggests a membranous-coating-mediated mechanism for transsynaptic communication. J Comp Neurol 2013; 521(1): 203-212
17. Li K, Wohlford-Lenane C, Perlman S, Zhao J, Jewell AK, Reznikov LR, Gibson-Corley KN, Meyerholz DK, McCray PB Jr. Middle East respiratory syndrome coronavirus causes multiple organ damage and lethal disease in mice transgenic for human dipeptidyl peptidase 4. J Infect Dis 2016; 213(5): 712-722

18. Dubé M, Le Coupanec A, Wong AHM, Rini JM, Desforges M, Talbot PJ. Axonal transport enables neuron-to-neuron propagation of human coronavirus OC43. J Virol 2018; 92(17): e00404-18

19. Netland J, Meyerholz DK, Moore S, Cassell M, Perlman S. Severe acute respiratory syndrome coronavirus infection causes neuronal death in the absence of encephalitis in mice transgenic for human ACE2. J Virol 2008; 82(15): 7264-7275

20. Lochhead JJ, Kellohen KL, Ronaldson PT, Davis TP. Distribution of insulin in trigeminal nerve and brain after intranasal administration. Sci Rep 2019; 9(1): 2621

21. Lochhead JJ, Thorne RG. Intranasal delivery of biologics to the central nervous system. Adv Drug Deliv Rev 2012; 64(7): 614-628

22. Ding Y, He L, Zhang Q, Huang Z, Che X, Hou J, Wang H, Shen H, Qiu L, Li Z, Geng J, Cai J, Han H, Li X, Kang W, Weng D, Liang P, Jiang S. Organ distribution of severe acute respiratory syndrome (SARS) associated coronavirus (SARS-CoV) in SARS patients: implications for pathogenesis and virus transmission pathways. $\mathrm{J}$ Pathol 2004; 203(2): 622-630

23. Gu J, Gong E, Zhang B, Zheng J, Gao Z, Zhong Y, Zou W, Zhan J, Wang S, Xie Z, Zhuang H, Wu B, Zhong H, Shao H, Fang W, Gao D, Pei F, Li X, He Z, Xu D, Shi X, Anderson VM, Leong AS. Multiple organ infection and the pathogenesis of SARS. J Exp Med 2005; 202(3): 415-424

24. Xu J, Zhong S, Liu J, Li L, Li Y, Wu X, Li Z, Deng P, Zhang J, Zhong N, Ding Y, Jiang Y. Detection of severe acute respiratory syndrome coronavirus in the brain: potential role of the chemokine Mig in pathogenesis. Clin Infect Dis 2005; 41(8): 1089-1096

25. Sun XF, Zhang X, Chen XH, Chen LW, Deng CH, Zou XJ, Liu WY, Yu HM. The infection evidence of SARS-COV-2 in ocular surface: a single-center cross-sectional study. medRxiv 2020; doi: 10.1101/ 2020.02.26.20027938

26. Baig AM, Khaleeq A, Ali U, Syeda H. Evidence of the COVID-19 virus targeting the CNS: tissue distribution, host-virus interaction, and proposed neurotropic mechanisms. ACS Chem Neurosci 2020; 11(7): 995-998

27. Arvin AM. Varicella-zoster virus. Clin Microbiol Rev 1996; 9(3): 361-381

28. Cohen JI. Varicella-zoster virus. The virus. Infect Dis Clin North Am 1996; 10(3): 457-468

29. Raj VS, Mou H, Smits SL, Dekkers DH, Müller MA, Dijkman R, Muth D, Demmers JA, Zaki A, Fouchier RA, Thiel V, Drosten C, Rottier PJ, Osterhaus AD, Bosch BJ, Haagmans BL. Dipeptidyl peptidase 4 is a functional receptor for the emerging human coronavirus-EMC. Nature 2013; 495(7440): 251-254

30. Qi F, Qian S, Zhang S, Zhang Z. Single cell RNA sequencing of 13 human tissues identify cell types and receptors of human coronaviruses. Biochem Biophys Res Commun 2020 Mar 19. [Epub ahead of print] doi: 10.1016/j.bbrc.2020.03.044

31. Li F. Structure, function, and evolution of coronavirus spike proteins. Annu Rev Virol 2016; 3(1): 237-261

32. Simmons G, Zmora P, Gierer S, Heurich A, Pöhlmann S. Proteolytic activation of the SARS-coronavirus spike protein: cutting enzymes 
at the cutting edge of antiviral research. Antiviral Res 2013; 100(3): 605-614

33. Wrapp D, Wang N, Corbett KS, Goldsmith JA, Hsieh CL, Abiona O, Graham BS, McLellan JS. Cryo-EM structure of the 2019-nCoV spike in the prefusion conformation. Science 2020; 367(6483): $1260-1263$

34. Imai Y, Kuba K, Penninger JM. The discovery of angiotensinconverting enzyme 2 and its role in acute lung injury in mice. Exp Physiol 2008; 93(5): 543-548

35. Li Z, Wu M, Yao JW, Guo J, Liao X, Song SJ, Li JL, Duan GJ, Zhou YX, Wu XJ, Zhou ZS, Wang TJ, Hu M, Chen XX, Fu Y, Lei C, Dong HL, Xu CO, Hu YH, Han M, Zhou Y, Jia HB, Chen XW, Yan JA. Caution on kidney dysfunctions of COVID-19 patients. medRxiv 2020; doi: 10.1101/2020.02.08.20021212

36. Xu H, Hou K, Xu H, Li Z, Chen H, Zhang N, Xu R, Fu H, Sun R, Wen L, Xie L, Liu H, Zhang K, Selvanayagam JB, Fu C, Zhao S, Yang Z, Yang M, Guo Y. Acute myocardial injury of patients with coronavirus disease 2019. medRxiv 2020; doi:10.1101/ 2020.03.05.20031591

37. Huang C, Wang Y, Li X, Ren L, Zhao J, Hu Y, Zhang L, Fan G, Xu J, Gu X, Cheng Z, Yu T, Xia J, Wei Y, Wu W, Xie X, Yin W, Li H, Liu M, Xiao Y, Gao H, Guo L, Xie J, Wang G, Jiang R, Gao Z, Jin Q, Wang J, Cao B. Clinical features of patients infected with 2019 novel coronavirus in Wuhan, China. Lancet 2020; 395(10223): 497 506

38. Hamming I, Timens W, Bulthuis ML, Lely AT, Navis G, van Goor H. Tissue distribution of ACE2 protein, the functional receptor for SARS coronavirus. A first step in understanding SARS pathogenesis. J Pathol 2004; 203(2): 631-637

39. Henry C, Zaizafoun M, Stock E, Ghamande S, Arroliga AC, White HD. Impact of angiotensin-converting enzyme inhibitors and statins on viral pneumonia. Proc Bayl Univ Med Cent 2018; 31(4): 419423

40. Moore MJ, Dorfman T, Li W, Wong SK, Li Y, Kuhn JH, Coderre J, Vasilieva N, Han Z, Greenough TC, Farzan M, Choe H. Retroviruses pseudotyped with the severe acute respiratory syndrome coronavirus spike protein efficiently infect cells expressing angiotensin-converting enzyme 2. J Virol 2004; 78(19): 1062810635

41. Tan WSD, Liao W, Zhou S, Mei D, Wong WF. Targeting the reninangiotensin system as novel therapeutic strategy for pulmonary diseases. Curr Opin Pharmacol 2018; 40: 9-17

42. Chen H, Guo J, Wang C, Luo F, Yu X, Zhang W, Li J, Zhao D, Xu D, Gong Q, Liao J, Yang H, Hou W, Zhang Y. Clinical characteristics and intrauterine vertical transmission potential of COVID-19 infection in nine pregnant women: a retrospective review of medical records. Lancet 2020; 395(10226): 809-815

43. Guan W, Ni Z, Hu Y, Liang W, Ou C, He J, Liu L, Shan H, Lei C, Hui D SC, Du B, Li L, Zeng G, Yuen KY, Chen R, Tang C, Wang T, Chen P, Xiang J, Li S, Wang J, Liang Z, Peng Y, Wei L, Liu Y, Hu Y, Peng P, Wang J, Liu J, Chen Z, Li G, Zheng Z, Qiu S, Luo J, Ye C, Zhu S, Zhong N. Clinical characteristics of 2019 novel coronavirus infection in China. medRxiv 2020; doi: 10.1101/ 2020.02.06.20020974

44. Holshue ML, DeBolt C, Lindquist S, Lofy KH, Wiesman J, Bruce H, Spitters C, Ericson K, Wilkerson S, Tural A, Diaz G, Cohn A, Fox L, Patel A, Gerber SI, Kim L, Tong S, Lu X, Lindstrom S,
Pallansch MA, Weldon WC, Biggs HM, Uyeki TM, Pillai SK; Washington State 2019-nCoV Case Investigation Team. First case of 2019 novel coronavirus in the United States. N Engl J Med 2020; 382(10): 929-936

45. Xiao F, Tang M, Zheng X, Li C, He J, Hong Z, Huang S, Zhang Z, Lin X, Fang Z, Lai R, Chen S, Liu J, Huang J, Xia J, Li Z, Jiang G, Liu Y, Li X, Shan H. Evidence for gastrointestinal infection of SARS-CoV-2. medRxiv 2020; doi: 10.1101/ 2020.02.17.20023721

46. Chen H, Xuan B, Yan Y, Zhu X, Shen C, Zhao G, Ji L, Xu D, Xiong H, Yu TC, Li X, Liu Q, Chen Y, Cui Y, Hong J, Fang JY. Profiling ACE2 expression in colon tissue of healthy adults and colorectal cancer patients by single-cell transcriptome analysis. medRxiv 2020; doi: 10.1101/2020.02.15.20023457

47. Li H, Wu C, Yang Y, Liu Y, Zhang P, Wang Y, Wang Q, Xu Y, Li M, Zheng M, Chen L. Furin, a potential therapeutic target for COVID-19. chinaXiv 2020; http://chinaxiv.org/abs/202002.00062

48. Li W, Zhu Y, Li Y, Shu M, Wen Y, Gao X, Wan C. The gut microbiota of hand, foot and mouth disease patients demonstrates down-regulated butyrate-producing bacteria and up-regulated inflammation-inducing bacteria. Acta Paediatr 2019; 108(6): 1133-1139

49. Chen L, Li L, Han Y, Lv B, Zou S, Yu Q. Tong-fu-li-fei decoction exerts a protective effect on intestinal barrier of sepsis in rats through upregulating ZO-1/occludin/claudin-1 expression. J Pharmacol Sci 2020 Feb 28. [Epub ahead of print] doi: 10.1016/j.jphs.2020.02.009

50. Fernández-Blanco JA, Estévez J, Shea-Donohue T, Martínez V, Vergara P. Changes in epithelial barrier function in response to parasitic infection: implications for IBD pathogenesis. J Crohn's Colitis 2015; 9(6): 463-476

51. Romani L, Del Chierico F, Chiriaco M, Foligno S, Reddel S, Salvatori G, Cifaldi C, Faraci S, Finocchi A, Rossi P, Bagolan P, D'Argenio P, Putignani L, Fusaro F. Gut mucosal and fecal microbiota profiling combined to intestinal immune system in neonates affected by intestinal ischemic injuries. Front Cell Infect Microbiol 2020; 10: 59

52. Khoury-Hanold W, Yordy B, Kong P, Kong Y, Ge W, Szigeti-Buck K, Ralevski A, Horvath TL, Iwasaki A. Viral spread to enteric neurons links genital HSV-1 infection to toxic megacolon and lethality. Cell Host Microbe 2016; 19(6): 788-799

53. Matsuda K, Park CH, Sunden Y, Kimura T, Ochiai K, Kida H, Umemura $T$. The vagus nerve is one route of transneural invasion for intranasally inoculated influenza a virus in mice. Vet Pathol 2004; 41(2): 101-107

54. Hosseini S, Wilk E, Michaelsen-Preusse K, Gerhauser I, Baumgärtner W, Geffers R, Schughart K, Korte M. Long-term neuroinflammation induced by influenza A virus infection and the impact on hippocampal neuron morphology and function. J Neurosci 2018; 38 (12): 3060-3080

55. Zhao JM, Zhou GD, Sun YL, Wang SS, Yang JF, Meng EH, Pan D, Li WS, Zhou XS, Wang YD, Lu JY, Li N, Wang DW, Zhou BC, Zhang TH. Clinical pathology and pathogenesis of severe acute respiratory syndrome. Chin J Exp Clin Virol (Zhonghua Shi Yan He Lin Chuang Bing Du Xue Za Zhi) 2003; 17(3): 217-221 (in Chinese)

56. Xiao Y, Meng Q, Yin X, Guan Y, Liu Y, Li C, Wang M, Liu G, Tong T, Wang LF, Kong X, Wu D. Pathological changes in masked 
palm civets experimentally infected by severe acute respiratory syndrome (SARS) coronavirus. J Comp Pathol 2008; 138(4): 171179

57. Yucel Y, Gupta N. Lymphatic drainage from the eye: a new target for therapy. Prog Brain Res 2015; 220: 185-198

58. Zhang Z, Helman JI, Li LJ. Lymphangiogenesis, lymphatic endothelial cells and lymphatic metastasis in head and neck cancer-a review of mechanisms. Int J Oral Sci 2010; 2(1): 5-14

59. Nedumpun T, Sirisereewan C, Thanmuan C, Techapongtada P, Puntarotairung R, Naraprasertkul S, Thanawongnuwech R, Suradhat $\mathrm{S}$. Induction of porcine reproductive and respiratory syndrome virus (PRRSV)-specific regulatory $\mathrm{T}$ lymphocytes (Treg) in the lungs and tracheobronchial lymph nodes of PRRSV-infected pigs. Vet Microbiol 2018; 216: 13-19

60. Khomich OA, Kochetkov SN, Bartosch B, Ivanov AV. Redox biology of respiratory viral infections. Viruses 2018; 10(8): E392

61. McCray PB Jr, Pewe L, Wohlford-Lenane C, Hickey M, Manzel L,
Shi L, Netland J, Jia HP, Halabi C, Sigmund CD, Meyerholz DK, Kirby P, Look DC, Perlman S. Lethal infection of K18-hACE2 mice infected with severe acute respiratory syndrome coronavirus. J Virol 2007; 81(2): 813-821

62. Louveau A, Smirnov I, Keyes TJ, Eccles JD, Rouhani SJ, Peske JD, Derecki NC, Castle D, Mandell JW, Lee KS, Harris TH, Kipnis J. Structural and functional features of central nervous system lymphatic vessels. Nature 2015; 523(7560): 337-341

63. Cheng Y, Haorah J. How does the brain remove its waste metabolites from within? Int J Physiol Pathophysiol Pharmacol 2019; 11(6): 238-249

64. Cashion MF, Banks WA, Bost KL, Kastin AJ. Transmission routes of HIV-1 gp120 from brain to lymphoid tissues. Brain Res 1999; 822(1-2): 26-33

65. Dhuria SV, Hanson LR, Frey WH 2nd. Intranasal delivery to the central nervous system: mechanisms and experimental considerations. J Pharm Sci 2010; 99(4): 1654-1673 